\title{
Article \\ The Nutritional Profile and On-Pack Marketing of Toddler-Specific Food Products Launched in Australia between 1996 and 2020
}

\author{
Jennifer R. McCann *(D), Catherine G. Russell (D) and Julie L. Woods (D)
}

check for updates

Citation: McCann, J.R.; Russell, C.G.; Woods, J.L. The Nutritional Profile and On-Pack Marketing of Toddler-Specific Food Products Launched in Australia between 1996 and 2020. Nutrients 2022, 14, 163. https://doi.org/10.3390/nu14010163 Academic Editor: Ekhard E. Ziegler

Received: 13 December 2021 Accepted: 29 December 2021 Published: 30 December 2021

Publisher's Note: MDPI stays neutral with regard to jurisdictional claims in published maps and institutional affiliations.

Copyright: (C) 2021 by the authors. Licensee MDPI, Basel, Switzerland. This article is an open access article distributed under the terms and conditions of the Creative Commons Attribution (CC BY) license (https:// creativecommons.org/licenses/by/ $4.0 /)$.
Institute for Physical Activity and Nutrition (IPAN), School of Exercise and Nutrition Sciences, Faculty of Health, Deakin University, Geelong, VIC 3220, Australia; georgie.russell@deakin.edu.au (C.G.R.); j.woods@deakin.edu.au (J.L.W.)

* Correspondence: j.mccann@deakin.edu.au

\begin{abstract}
With the food system evolving, it is not clear how the nutrition and on-pack claims of toddler foods have been impacted. Data on the trends in Australia are lacking, so we sought to determine the changes in the nutrition and on-pack claims of toddler-specific packaged foods over time. A retrospective cross-sectional analysis was conducted using the Mintel Global New Products Database. The number of toddler-specific foods increased from 1996 to 2020. Over time, a lower proportion of meals and snacks were classified as "ultra-processed", but a higher proportion of snacks were classified as "discretionary". Meals launched after 2014 had higher median values for energy, saturated fat, and sugar than those in earlier years. Toddler snacks launched after 2014 had lower median values for sodium, and higher median values for fat, saturated fat, and sugar than those in earlier years. The mean number of total claims per package increased over time for snacks, with an increase in unregulated claims for both meals and snacks. Public health action is needed to ensure that the retail food environment for young children is health-promoting, including stringent and clear regulations for on-pack claims, and compositional guidelines and guidance on how to reduce the number of ultra-processed foods for toddlers.
\end{abstract}

Keywords: ultra-processed; nutrition; public health; toddler; food environment

\section{Introduction}

In Australia, poor diet quality and childhood overweight and obesity are major public health issues [1-3]. The causes of these problems are multifactorial; however, the food environment is increasingly recognised as an important contributor [4-6]. Because of a major shift in the global food system in Western countries such as Australia, ultra-processed (UP) and discretionary foods contribute close to $50 \%$ of the total dietary intake in young children [3,7-10]. There is strong evidence on the harms of UP food consumption on the paediatric population $[8,11,12]$, which include impeding continued breastfeeding [8], overweight and obesity [13], and altering the taste palate [14,15].

A key aspect of the food system is on-pack marketing, which influences consumer purchases of UP and discretionary foods [16-21]. Consumers are often confused by claims and are potentially being misled by on-pack claims into thinking foods are healthier than they really are [22-24]. While it is known that the food system has evolved over time, it is unclear how the nutrition profile and on-pack marketing of toddler foods has changed as a part of this. With real-world data on trends over time in the retail toddler food space in Australia lacking, the aim of this study was to determine the changes over time in the nutritional profile and on-pack claims in toddler-specific packaged foods launched in the Australian retail market. 


\section{Materials and Methods}

The Mintel Global New Products Database (Mintel) was searched for the following predefined categories: baby biscuits and rusks; baby cereals; baby fruit products, desserts and yogurts; baby juices and drinks; baby savoury meals and dishes; baby snacks; and other baby food, in the Australian retail market from June 1996 (inception of Mintel) to December 2020 (no foods are categorised as "toddler" in the Mintel database). All product images, nutrients from the nutrition information panel, ingredient lists, and on-pack claims were exported into an MS Excel file. After exporting, to determine their inclusion as toddler food (1-3 years), the product images, information, and descriptions were manually checked for the age range they were being marketed to.

All on-pack claims were counted and subclassified as "regulated" and "unregulated", as per Schedule 4 of the Food Standards Australia New Zealand (FSANZ) Food Standards Code [25]. Regulated claims included nutrition-content claims (e.g., "no added sugar") and health claims (e.g., "calcium for strong bones"), while unregulated claims included health-related ingredients (e.g., "no added preservatives"), natural/organic claims (e.g., "all natural" or "certified organic"), environmental claims (recycled logo), and others (e.g., "perfect for small hands").

Products were classified in three ways: as "meals" or "snacks", based on the categories identified in a 2019 World Health Organization report [26]; as "core" or "discretionary", based on the Australian Dietary Guidelines [27] and the Australian Bureau of Statistics discretionary food list [28]; and by the level of processing as per the NOVA classification (ultra-processed (UP), processed (P), and minimally processed (MP)) [29].

\section{Data Analysis}

All analyses were conducted using SPSS V26. Data were split into time quartiles (T1 (1996-2002), T2 (2003-2008), T3 (2009-2014), and T4 (2015-2020)) to explore the changes over time. Meals and snacks were analysed separately because of the different nutritional profiles and classifications (meals are classified as "core" products according to the ADG, while many snacks are not). For each time period, descriptive analyses were performed to determine the number and proportions of the products launched, the food type classifications, the median nutrient values, and the means and ranges of different types of claims. Kruskal-Wallis tests and ANOVA tested for differences in the median nutrient values and mean claim types across each time quartile, while Chi-square tested for the ADG and NOVA classification significance across time periods. The significance levels were set at the acceptable minimum significance level of $<0.05$.

\section{Results}

\subsection{Total Products}

A total of 213 products (39 meals and 174 snacks) were identified. Of these, ten had no photos or descriptive data (nine in T1 (eight snacks and one meal), and one snack in T2), and so these were excluded from all analyses, except the total number of products. In $\mathrm{T} 1$, there were two meals and eight snacks. There was one meal in T1 with photos and descriptive data, and this was a core and UP product. More detail for time-periods $2-4$ can be seen in Table 1 . The majority ( $82 \%$ ) of products were snack foods. There were equal proportions of core (50\%) and discretionary (50\%) foods, and $76 \%$ of all products were classified as UP. 
Table 1. Number of products launched in Time-periods 2-4, and classifications within ADG and NOVA.

\begin{tabular}{|c|c|c|c|c|c|c|c|c|c|}
\hline & \multicolumn{3}{|c|}{ Meals } & \multicolumn{3}{|c|}{ Snacks } & \multicolumn{3}{|c|}{ Total Products } \\
\hline & $n$ & $\begin{array}{c}\text { ADG }^{1} \\
\text { Core } \\
n(\%)\end{array}$ & $\begin{array}{c}\text { NOVA } \\
\text { UP } 2 * \\
n(\%)\end{array}$ & $n$ & $\begin{array}{l}\text { ADG } \\
\text { Core }^{* *} \\
n(\%)\end{array}$ & $\begin{array}{c}\text { NOVA } \\
\text { UP ** } \\
n(\%)\end{array}$ & $n$ & $\begin{array}{l}\text { ADG } \\
\text { Core } * * \\
n(\%)\end{array}$ & $\begin{array}{l}\text { NOVA } \\
\text { UP ** } \\
n(\%)\end{array}$ \\
\hline $\begin{array}{c}\text { Time-period } 2 \\
(2003-2008)\end{array}$ & 7 & $7(100)$ & $6(86)$ & $17^{3}$ & $7(41)$ & $15(88)$ & 25 & $14(56)$ & $21(84)$ \\
\hline $\begin{array}{c}\text { Time-period } 3 \\
(2009-2014)\end{array}$ & 19 & 19(100) & $13(68)$ & 58 & $30(52)$ & $51(88)$ & 77 & $49(64)$ & $64(83)$ \\
\hline $\begin{array}{l}\text { Time-period } 4 \\
(2015-2020)\end{array}$ & 11 & 11(100) & $5(45)$ & 90 & $27(30)$ & $70(78)$ & 101 & $38(38)$ & $75(74)$ \\
\hline
\end{tabular}

${ }^{*} p<0.05,{ }^{* *} p<0.001, \chi^{2}$. T1 excluded because of no available on-pack data. ${ }^{1}$ ADG: Australian Dietary Guidelines; ${ }^{2}$ UP: ultra-processed. ${ }^{3}$ Total numbers have been adjusted to exclude the products without photos or descriptive data.

\subsection{Results over Time}

NOVA and Australian Dietary Guidelines Classifications

More products were launched in each time period compared to the previous, as seen in Table 1. Snacks showed some fluctuation in classification within the ADG and NOVA over time: In T2, $41 \%$ of snacks were classified as "core", and $88 \%$ were classified as "UP"; in T3, 52\% were classified as "core", and 88\% were classified as "UP"; and in T4, 30\% were classified as "core", and 78\% were classified as "UP". The changes in the classifications of snacks by the ADG and NOVA across time periods were statistically significant (both $p<0.001)$. The proportion of meals classified according to the ADG did not change over time, with all meals being classified as "core"; however, there were changes in the NOVA classification, with a reduction in the proportion of products classified as "UP" between T2 $(86 \%)$ and T4 $(45 \%)(p<0.05)$.

\subsection{Nutritional Characteristics}

The median nutrient values per $100 \mathrm{~g}$ for both meals and snacks during time-periods 2-4 are shown in Table 2. For meals, there were no significant differences in the median nutrient values in each time period. For snacks, there were significant differences in the median energy, total fat, and saturated fat values across the time periods (all $p<0.05)$, although the differences are very small and are unlikely to be nutritionally important.

Table 2. Median nutrient values/100 g and (interquartile range) of meals and snacks launched in time-periods 2, 3, and 4 .

\begin{tabular}{ccccccc}
\hline & $\begin{array}{c}\text { Meals T2 } \\
\boldsymbol{n = 7}\end{array}$ & $\begin{array}{c}\text { Meals T3 } \\
\boldsymbol{n = 1 9}\end{array}$ & $\begin{array}{c}\text { Meals T4 } \\
\boldsymbol{n = 1 1}\end{array}$ & $\begin{array}{c}\text { Snacks T2 } \\
\boldsymbol{n = 1 7}\end{array}$ & $\begin{array}{c}\text { Snacks T3 } \\
\boldsymbol{n = 5 8}\end{array}$ & $\begin{array}{c}\text { Snacks T4 } \\
\boldsymbol{n}=\mathbf{9 0}\end{array}$ \\
\hline Energy (kJ) & $276(247)$ & $304(150)$ & $395(183)$ & $1600(270)$ & $1481.7(1275)$ & $1657 *(382)$ \\
Protein (g) & $3.9(6)$ & $3.5(2)$ & $3.9(3)$ & $7.1(6)$ & $5.2(5)$ & $5.5(5)$ \\
Total fat (g) & $2.9(9)$ & $2.0(1)$ & $2.1(2)$ & $6.3(9)$ & $3.7(8)$ & $6.5 *(14)$ \\
Saturated fat (g) & $0.5(1)$ & $0.6(1)$ & $0.8(2)$ & $2.3(3)$ & $1.2(3)$ & $2.5 *(3)$ \\
Carbohydrate (g) & $9.4(5)$ & $9.8(4)$ & $9.2(4)$ & $65.1(22)$ & $65.9(58)$ & $65.9(18)$ \\
Sugar (g) & $2.3(3)$ & $2.5(1)$ & $2.5(1)$ & $19.3(31)$ & $14.8(30)$ & $23(34)$ \\
Sodium (mg) & $60(55)$ & $30(75)$ & $55(70)$ & $95(234)$ & $73(194)$ & $32(192)$ \\
\hline
\end{tabular}

* $p \leq 0.05$ for across all time periods. T1 excluded because of no available on-pack data. T2: Time-period 2 (2003-2008); T3: Time-period 3 (2009-2014); T4: Time-period 4 (2014-2020). ${ }^{1}$ Total numbers have been adjusted to exclude the products without photos or descriptive data.

\subsection{On-Pack Claims}

The total numbers, mean numbers, and ranges of each type of unregulated and regulated claims across the time periods are detailed in Table 3. For meals, the only difference in the mean numbers of claims were related to unregulated environmental claims, with all other regulated and unregulated claims not demonstrating any differences 
across the time periods. The mean number of unregulated health-related ingredient claims, natural/organic claims, and other claims were significantly different across the time periods for snacks (all $p<0.05)$.

Table 3. Mean numbers (ranges) of claims per product by type for meals and snacks launched in time-periods 2, 3, and 4 .

\begin{tabular}{|c|c|c|c|c|c|c|}
\hline & Meals T2 & Meals T3 & Meals T4 & Snacks T2 ${ }^{1}$ & Snacks T3 & Snacks T4 \\
\hline & $n=7$ & $n=19$ & $n=11$ & $n=17$ & $n=58$ & $n=90$ \\
\hline $\begin{array}{c}\text { Unregulated } \\
\text { health-related } \\
\text { ingredient claims } \\
\quad(n=774)\end{array}$ & $3(1-5)$ & $3(0-6)$ & $3(1-6)$ & $3(0-7)$ & $4(0-8)$ & $4(0-10) *$ \\
\hline $\begin{array}{c}\text { Unregulated } \\
\text { natural/organic } \\
\text { claims }(n=102)\end{array}$ & $0(0-2)$ & $1(0-1)$ & $1(0-1)$ & $0(0-2)$ & $0(0-2)$ & $1(0-3) *$ \\
\hline $\begin{array}{c}\text { Unregulated } \\
\text { environmental claims } \\
(n=101)\end{array}$ & $0(0)$ & $0(0-1)$ & $0(0-2) * *$ & $0(0-1)$ & $1(0-2)$ & $1(0-3)$ \\
\hline $\begin{array}{l}\text { Unregulated "other" } \\
\text { claims }(n=96)\end{array}$ & $0(0)$ & $0(0-1)$ & $0(0-5)$ & $0(0-1)$ & $0(0-1)$ & $1(0-7)^{*}$ \\
\hline $\begin{array}{c}\text { Regulated } \\
\text { nutrition-content } \\
\text { claims }(n=216)\end{array}$ & $2(0-5)$ & $1(1-4)$ & $1(0-4)$ & $1(0-4)$ & $1(0-4)$ & $1(0-4)$ \\
\hline $\begin{array}{l}\text { Regulated health } \\
\text { claims }(n=33)\end{array}$ & $1(0-5)$ & $0(0)$ & $0(0)$ & $0(0-1)$ & $0(0-6)$ & $0(0-3)$ \\
\hline $\begin{array}{l}\text { Total unregulated } \\
\text { claims }(n=1073)\end{array}$ & $3(1-6)$ & $3(0-7)$ & $3(5-8)$ * & $4(0-9)$ & $5(0-10)$ & $7(2-13) * *$ \\
\hline $\begin{array}{l}\text { Total regulated claims } \\
\qquad(n=249)\end{array}$ & $3(0-10)$ & $1(0-4)$ & $1(0-4)$ & $1(0-4)$ & $1(0-10)$ & $1(0-4)$ \\
\hline Total claims $(n=1322)$ & $6(3-11)$ & $5(0-9)$ & $5(5-12) *$ & $5(0-10)$ & $6(0-18)$ & $8(2-14) * *$ \\
\hline
\end{tabular}

\section{Discussion}

Our results show that there were relatively more toddler-specific packaged foods (meals and snacks) launched onto the Australian retail market at each of the four time periods investigated. Notably, substantially more toddler-specific snack foods were launched during T3 (2009-2014) and T4 (2015-2020) than in T1 (1996-2002) and T2 (2003-2008). In relation to the healthiness of foods launched during the time periods, the findings were mixed, with a lower percentage of meals classified as "UP" in T4 than in earlier time periods, and a lower percentage of snacks classified as "UP" and "core" during T3 and T4 than in T2. While the proportion of UP toddler-specific foods on the Australian retail market decreased over time, this was paralleled by an increase in toddler snacks classified as "discretionary". The mean number of total claims remained relatively stable over time on meals but was higher in T3 and T4 compared to T2 on snacks, which is due to an increase in unregulated claims.

The finding of a greater number of new products launched in T4 compared to other time periods concurs with Australian and global retail data, which shows an expansion of the toddler-specific food and milk markets over time [30,31]. The majority of new products (74\%) launched over the 25-year timeframe of this study were UP. This aligns with analyses of the current toddler retail market, which reflect the cumulative effects of product launches and cessations over time, and that have shown that most toddler-specific foods in the retail market are toddler-specific packaged snacks and are UP [32,33]. We found a large decrease in the percentage of meals classified as "UP" from T2 (86\%) through to T4 (45\%); however, all meals across all time periods were classified as "core" foods. In addition, despite the lower percentage of UP snacks launched in T4, which may represent an acknowledgement of the harms associated with these foods by manufacturers, there was a higher percentage 
of discretionary snacks launched at the same time. The food environment, therefore, still favours foods not recommended for toddlers.

That the toddler retail market is largely UP and discretionary is concerning, as the harmful effects of a diet high in UP and discretionary foods on the health of the paediatric population are well documented $[8,13,14,34,35]$. Despite the percentage of UP toddlerspecific foods decreasing from T2 $(84 \%)$ to T3 $(83 \%)$, overall, $74 \%$ of all products at T4 were still UP. Paralleling this decrease in the percentage of UP products, the percentage of discretionary snack foods increased at each time point from T2 to T4. At a young age, the normalisation of UP and discretionary foods, which are often salty, fatty, or sweet, and homogenous in texture $[11,33,36]$, can have detrimental impacts on the formation of eating behaviours, and can have ongoing effects on diet and health. [36-38] Instead, young children should be exposed to a variety of tastes, flavours, and textures in the critical early years to develop healthy eating habits $[39,40]$.

Nutrient composition across all products appears to have remained similar over time, despite changes in the NOVA classification. This may be partly explained by the fact that the predominant type of snack food was fruit-based cereal bars, and some reformulation over time may have occurred. The small changes in nutrient compositions seen may align with product reformulation within this retail market [41-44], as snacks were seen to have lower median sodium, sugar, and carbohydrate levels at T3 as compared to T2, with sugar increasing at T4. Global research over various time periods reports toddler foods to be high in sugar and/or sodium [45-49]. In addition, an Australian study reported that from $2009-2011,67 \%$ of child-oriented food products underwent reformulation, with $15 \%$ having simultaneous positive (e.g., reduction in sodium) and negative (e.g., increase in sugar) reformulations, and overall little improvement in healthiness. [50] Within the food industry, the current state of practise is very nutrient-centric [51], with most reformulation efforts focusing on reducing sugar or sodium levels. However, there are limits to which nutrients can be reduced within a UP food before further additives are required to retain the hyper-palatability of the food. This nutrient-centric view of reformulation appears to be promoting the consumption of UP food through on-pack claims and messaging [52].

Claims on products remained quite similar across all products and all time periods, apart from the unregulated claims relating to no additives, organic claims, and "other" claims (claims related to being "good for small tummies", "easy to hold", or story-based messaging about the company). Despite the seemingly small changes in the number of claims on these products, the mean number of claims (and the maximum number of claims) per product was high for both meals (mean $=5$, $\max =12$ ) and snacks $($ mean $=8, \max =14$ ), and is comparable to research from the United States on infant and toddler foods [53]. Evidence shows that baby and toddler packaged foods often include numerous on-pack claims, both regulated and unregulated (depending on the country) [32,53,54]. Claims on food packaging have been shown to influence consumer purchasing $[16,22,55,56]$, and they can create an increase in health perceptions for many products $[16,57]$. This can then mislead consumers, as unhealthy foods can appear healthier by their presence, for instance, by only making claims about positive nutrient characteristics (e.g., "low sugar" or "low sodium"), while being high in nutrients of concern (e.g., the product may be low-sugar but have a high sodium content). The majority of these foods are either discretionary choices or UP, and are, therefore, not recommended for toddlers, and yet companies are permitted to display these claims. Indeed, Australian food regulation permits the use of nutrient content claims on all foods, regardless of the overall nutrition profile or the level of processing.

\section{Limitations}

This study provides some insights into the practices of toddler food manufacturers over time but does not enable a thorough and detailed examination of the whole toddler food environment at all points along the timeframe covered. It is possible that some foods may have been missed within the Mintel database because of the manual nature of identifying toddler foods. The classification of foods by ADGs and NOVA can be difficult 
occasionally, but a 10\% sample of products was double-checked for accuracy to help limit misclassifications, of which there were none.

\section{Conclusions}

Our results demonstrate that, despite a decrease over time in the percentage of foods classified as UP, toddler-specific foods being launched into the Australian retail market are highly processed (and have been since 1996, at least), and toddler snack foods are mostly discretionary choices, and are not recommended by the ADG. Despite these results, these products are being promoted to parents of young children, often with on-pack claims indicating that they are healthy. To promote the launch of healthier toddler foods onto the Australian retail market, public health action is needed. This includes stringent and clear labelling regulations for on-pack claims, clear guidelines to reduce the number of UP foods being marketed for toddlers, and compositional guidelines for foods made for toddlers.

Author Contributions: Conceptualization, J.R.M. and J.L.W.; methodology, J.R.M. and J.L.W.; formal analysis, J.R.M.; data curation, J.R.M.; writing—original draft preparation, J.R.M.; writing-review and editing, J.R.M., J.L.W. and C.G.R.; supervision, J.L.W. and C.G.R. All authors have read and agreed to the published version of the manuscript.

Funding: This research received no external funding.

Institutional Review Board Statement: Not applicable.

Data Availability Statement: Mintel database is not publicly available; however, select data for research purposes can be made available upon request to the corresponding author.

Conflicts of Interest: The authors declare no conflict of interest.

\section{References}

1. Australian Institute of Health and Welfare. Nutrition across the Life Stages; Cat. No. PHE 227; Australian Institute of Health and Welfare: Canberra, Australia, 2018.

2. Bell, L.K.; Golley, R.; Daniels, L.; Magarey, A. Dietary patterns of Australian children aged 14 and 24 months, and associations with socio-demographic factors and adiposity. Eur. J. Clin. Nutr. 2013, 67, 638-645. [CrossRef]

3. Spence, A.C.; Campbell, K.J.; Lioret, S.; McNaughton, S. Early Childhood Vegetable, Fruit, and Discretionary Food Intakes Do Not Meet Dietary Guidelines, But Do Show Socioeconomic Differences and Tracking over Time. J. Acad. Nutr. Diet. 2018, 118, 1634-1643.e1. [CrossRef] [PubMed]

4. Birch, L.L.; Anzman, S.L. Learning to Eat in an Obesogenic Environment: A Developmental Systems Perspective on Childhood Obesity. Child Dev. Perspect. 2010, 4, 138-143. [CrossRef]

5. Swinburn, B.; Kraak, V.; Rutter, H.; Vandevijvere, S.; Lobstein, T.; Sacks, G.; Gomes, F.; Marsh, T.; Magnusson, R. Strengthening of accountability systems to create healthy food environments and reduce global obesity. Lancet 2015, 385, 2534-2545. [CrossRef]

6. Zobel, E.H.; Hansen, T.; Rossing, P.; Von Scholten, B.J. Global Changes in Food Supply and the Obesity Epidemic. Curr. Obes. Rep. 2016, 5, 449-455. [CrossRef]

7. Coxon, C.; Devenish, G.; Ha, D.; Do, L.; Scott, J.A. Sources and Determinants of Discretionary Food Intake in a Cohort of Australian Children Aged 12-14 Months. Int. J. Environ. Res. Public Health 2019, 17, 80. [CrossRef]

8. Khandpur, N.; Neri, D.A.; Monteiro, C.; Mazur, A.; Frelut, M.-L.; Boyland, E.; Weghuber, D.; Thivel, D. Ultra-Processed Food Consumption among the Paediatric Population: An Overview and Call to Action from the European Childhood Obesity Group. Ann. Nutr. Metab. 2020, 76, 109-113. [CrossRef]

9. Batalha, M.A.; da França, A.K.T.C.; da Conceição, S.I.O.; dos Santos, A.M.; de Silva, F.S.; Padilha, L.L.; da Silva, A.A.M. Processed and Ultra-Processed Food Consumption among Children Aged 13 to 35 Months and Associated Factors. Cad. Saúde Pública 2017, 33. [CrossRef] [PubMed]

10. Karnopp, E.V.; Vaz, J.D.; Schafer, A.A.; Muniz, L.C.; Souza, R.D.; Santos, I.D.; Gigante, D.P.; Assunção, M.C. Food consumption of children younger than 6 years according to the degree of food processing. J. Pediatr. (Rio J.) 2017, 93, 70-78. [CrossRef]

11. Elizabeth, L.; Machado, P.; Zinöcker, M.; Baker, P.; Lawrence, M. Ultra-Processed Foods and Health Outcomes: A Narrative Review. Nutrients 2020, 12, 1955. [CrossRef]

12. Global Food Research Program. Ultra-Processed Foods: A Global Threat to Public Health; University of North Carolina at Chapel Hill: Chapel Hill, NC, USA, 2021.

13. Costa, C.S.; Del-Ponte, B.; Assunção, M.C.F.; Santos, I.S. Consumption of ultra-processed foods and body fat during childhood and adolescence: A systematic review. Public Health Nutr. 2018, 21, 148-159. [CrossRef] [PubMed] 
14. De Montemor Marçal, G.; e Mendes, M.M.; Fragoso, M.D.G.M.; Florêncio, T.M.D.M.T.; Bueno, N.B.; Clemente, A.P.G. Association between the consumption of ultra-processed foods and the practice of breast-feeding in children under 2 years of age who are beneficiaries of the conditional cash transfer programme, Bolsa Família. Public Health Nutr. 2021, 24, 3313-3321. [CrossRef] [PubMed]

15. Hardwick, J.; Sidnell, A. Infant nutrition-Diet between 6 and 24 months, implications for paediatric growth, overweight and obesity. Nutr. Bull. 2014, 39, 354-363. [CrossRef]

16. Devia, G.; Forli, S.; Vidal, L.; Curutchet, M.R.; Ares, G. References to home-made and natural foods on the labels of ultra-processed products increase healthfulness perception and purchase intention: Insights for policy making. Food Qual. Prefer. 2021, 88, 104110. [CrossRef]

17. Duffy, E.W.; Taillie, L.S.; Richter, A.P.C.; Higgins, I.C.; Harris, J.L.; Hall, M.G. Toddler milk perceptions and purchases: The role of Latino ethnicity. Public Health Nutr. 2021, 24, 2911-2919. [CrossRef]

18. Harris, J.L.; Pomeranz, J.L. Infant formula and toddler milk marketing: Opportunities to address harmful practices and improve young children's diets. Nutr. Rev. 2020, 78, 866-883. [CrossRef]

19. Breen, M.; James, H.; Rangan, A.; Gemming, L. Prevalence of Product Claims and Marketing Buzzwords Found on Health Food Snack Products Does Not Relate to Nutrient Profile. Nutrients 2020, 12, 1513. [CrossRef]

20. García, A.L.; Morillo-Santander, G.; Parrett, A.; Mutoro, A.N. Confused health and nutrition claims in food marketing to children could adversely affect food choice and increase risk of obesity. Arch. Dis. Child. 2019, 104, 541-546. [CrossRef]

21. Koo, Y.-C.; Chang, J.-S.; Chen, Y.C. Food claims and nutrition facts of commercial infant foods. PLoS ONE 2018, 13, e0191982. [CrossRef] [PubMed]

22. Richter, A.P.C.; Duffy, E.W.; Taillie, L.S.; Harris, J.L.; Pomeranz, J.L.; Hall, M.G. The Impact of Toddler Milk Claims on Beliefs and Misperceptions: A Randomized Experiment with Parents of Young Children. J. Acad. Nutr. Diet. 2021. [CrossRef]

23. Malek, L.; Fowler, H.; Duffy, G.; Katzer, L. Informed choice or guessing game? Understanding caregivers' perceptions and use of infant formula labelling. Public Health Nutr. 2019, 22, 273-286. [CrossRef] [PubMed]

24. Mehta, K.; Phillips, C.; Ward, P.; Coveney, J.; Handsley, E.; Carter, P. Marketing foods to children through product packaging: Prolific, unhealthy and misleading. Public Health Nutr. 2012, 15, 1763-1770. [CrossRef] [PubMed]

25. Food Standards Australia New Zealand. Australia New Zealand Food Standards Code-Standard 1.2.7-Nutrition, Health and Related Claims. Available online: https:/ / www.legislation.gov.au/Series/F2015L00394 (accessed on 5 November 2018).

26. World Health Organization. Ending Inappropriate Promotion of Commercially Available Complementary Foods for Infants and Young Children between 6 and 36 Months in Europe; World Health Organization: Copenhagen, Denmark, 2019.

27. National Health and Medical Research Council. Dietary Guidelines for Children and Adolescents in Australia, Incorporating the Infant Feeding Guidelines for Health Workers; National Health and Medical Research Council: Canberra, Australia, 2003.

28. Australian Bureau of Statistics. Discretionary Foods; Australian Bureau of Statistics: Canberra, Australia, 2015.

29. Monteiro, C.A.; Cannon, G.; Moubarac, J.-C.; Levy, R.B.; Louzada, M.L.C.; Jaime, P.C. The UN Decade of Nutrition, the NOVA Food Classification and the Trouble with Ultra-Processing. Public Health Nutr. 2018, 21, 5-17. [CrossRef]

30. Baker, P.; Russ, K.; Kang, M.; Santos, T.M.; Neves, P.A.R.; Smith, J.; Kingston, G.; Mialon, M.; Lawrence, M.; Wood, B.; et al Globalization, first-foods systems transformations and corporate power: A synthesis of literature and data on the market and political practices of the transnational baby food industry. Glob. Health 2021, 17, 1-35. [CrossRef]

31. Baker, P.; Santos, T.; Neves, P.A.; Machado, P.; Smith, J.; Piwoz, E.; Barros, A.J.D.; Victora, C.G.; McCoy, D. First-food systems transformations and the ultra-processing of infant and young child diets: The determinants, dynamics and consequences of the global rise in commercial milk formula consumption. Matern. Child Nutr. 2021, 17, e13097. [CrossRef]

32. McCann, J.R.; Russell, G.C.; Campbell, K.J.; Woods, J.L. Nutrition and packaging characteristics of toddler foods and milks in Australia. Public Health Nutr. 2021, 24, 1153-1165. [CrossRef]

33. Grammatikaki, E.; Wollgast, J.; Caldeira, S. High Levels of Nutrients of Concern in Baby Foods Available in Europe That Contain Sugar-Contributing Ingredients or Are Ultra-Processed. Nutrients 2021, 13, 3105. [CrossRef] [PubMed]

34. Leffa, P.S.; Hoffman, D.J.; Rauber, F.; Sangalli, C.N.; Valmórbida, J.L.; Vitolo, M.R. Longitudinal associations between ultraprocessed foods and blood lipids in childhood. Br. J. Nutr. 2020, 124, 341-348. [CrossRef]

35. Rauber, F.; Campagnolo PD, B.; Hoffman, D.J.; Vitolo, M.R. Consumption of ultra-processed food products and its effects on children's lipid profiles: A longitudinal study. Nutr. Metab. Cardiovasc. Dis. 2015, 25, 116-122. [CrossRef]

36. Machado, P.P.; Steele, E.M.; Levy, R.B.; Sui, Z.; Rangan, A.; Woods, J.; Gill, T.; Scrinis, G.; Monteiro, C.A. Ultra-processed foods and recommended intake levels of nutrients linked to non-communicable diseases in Australia: Evidence from a nationally representative cross-sectional study. BMJ Open 2019, 9, e029544. [CrossRef]

37. Vandevijvere, S.; Jaacks, L.M.; Monteiro, C.A.; Moubarac, J.C.; Girling-Butcher, M.; Lee, A.C.; Pan, A.; Bentham, J.; Swinburn, B Global trends in ultra-processed food and drink product sales and their association with adult body mass index trajectories. Obes. Rev. 2019, 20, 10-19. [CrossRef]

38. Costa, C.; Rauber, F.; Leffa, P.D.S.; Sangalli, C.; Campagnolo, P.; Vitolo, M.R. Ultra-processed food consumption and its effects on anthropometric and glucose profile: A longitudinal study during childhood. Nutr. Metab. Cardiovasc. Dis. 2019, 29, 177-184. [CrossRef] [PubMed]

39. Mennella, J.A. Ontogeny of taste preferences: Basic biology and implications for health. Am. J. Clin. Nutr. 2014, 99, 704S-711S. [CrossRef] 
40. Schwartz, C.; Scholtens, P.A.; Lalanne, A.; Weenen, H.; Nicklaus, S. Development of healthy eating habits early in life. Review of recent evidence and selected guidelines. Appetite 2011, 57, 796-807. [CrossRef]

41. Velázquez, A.L.; Vidal, L.; Varela, P.; Ares, G. Sugar reduction in products targeted at children: Why are we not there yet? J. Sens. Stud. 2021, 36, e12666. [CrossRef]

42. Roberto, C.A.; Ng, S.W.; Ganderats-Fuentes, M.; Hammond, D.; Barquera, S.; Jauregui, A.; Taillie, L.S. The Influence of Front-ofPackage Nutrition Labeling on Consumer Behavior and Product Reformulation. Annu. Rev. Nutr. 2021, 41, 529-550. [CrossRef] [PubMed]

43. Spiteri, S.A.; Olstad, D.L.; Woods, J.L. Nutritional quality of new food products released into the Australian retail food market in 2015-Is the food industry part of the solution? BMC Public Health 2018, 18, 222. [CrossRef]

44. Morrison, H.; Meloncelli, N.; Pelly, F.E. Nutritional quality and reformulation of a selection of children's packaged foods available in Australian supermarkets: Has the Health Star Rating had an impact? Nutr. Diet. 2018, 76, 296-304. [CrossRef] [PubMed]

45. Cogswell, M.E.; Gunn, J.P.; Yuan, K.; Park, S.; Merritt, R. Sodium and Sugar in Complementary Infant and Toddler Foods Sold in the United States. Pediatrics 2015, 135, 416-423. [CrossRef]

46. Elliott, C.D.; Conlon, M.J. Packaged baby and toddler foods: Questions of sugar and sodium. Pediatr. Obes. 2014, 10, 149-155. [CrossRef] [PubMed]

47. Samuel, L.; Ethan, D.; Basch, C.H.; Samuel, B. A Comparative Study of the Sodium Content and Calories from Sugar in Toddler Foods Sold in Low- and High-Income New York City Supermarkets. Glob. J. Health Sci. 2014, 6, 22. [CrossRef] [PubMed]

48. Maalouf, J.; Cogswell, M.E.; Bates, M.; Yuan, K.; Scanlon, K.S.; Pehrsson, P.; Gunn, J.P.; Merritt, R.K. Sodium, sugar, and fat content of complementary infant and toddler foods sold in the United States. Am. J. Clin. Nutr. 2017, 105, 1443-1452. [CrossRef] [PubMed]

49. Ndanuko, R.N.; Dunford, E.K.; Wu, J.H.; Raubenheimer, D.; Neal, B. Changes in sodium levels of processed foods among the International Food and Beverage Association member companies in Australia: 2013-2017. J. Food Compos. Anal. 2020, 87, 103405. [CrossRef]

50. Savio, S.; Mehta, K.; Udell, T.; Coveney, J. A survey of the reformulation of Australian child-oriented food products. BMC Public Health 2013, 13, 836. [CrossRef] [PubMed]

51. Monteiro, C.A.; Cannon, G.; Lawrence, M.; Costa Louzada, M.D.; Pereira Machado, P. Ultra-Processed Foods, Diet Quality, and Health Using the NOVA Classification System; FAO: Rome, Italy, 2019.

52. Scrinis, G.; Monteiro, C.A. Ultra-processed foods and the limits of product reformulation. Public Health Nutr. 2018, 21, 247-252. [CrossRef]

53. Harris, J.L.; Schwartz, M.B.; Brownell, K.D. Baby Food FACTS: Nutrition and Marketing of Baby and Toddler Food and Drinks; UConn Rudd Center for Food Policy and Obesity: Hartford, CT, USA, 2016.

54. Public Health England. Foods and Drinks Aimed at Infants and Young Children: Evidence and Opportunities for Action; Public Health England: London, UK, 2019.

55. Franco-Arellano, B.; Vanderlee, L.; Ahmed, M.; Oh, A.; L'Abbé, M. Influence of front-of-pack labelling and regulated nutrition claims on consumers' perceptions of product healthfulness and purchase intentions: A randomized controlled trial. Appetite 2020, 149, 104629. [CrossRef]

56. Benson, T.; Lavelle, F.; McCloat, A.; Mooney, E.; Bucher, T.; Egan, B.; Dean, M. Are the Claims to Blame? A Qualitative Study to Understand the Effects of Nutrition and Health Claims on Perceptions and Consumption of Food. Nutrients 2019, 11, 2058. [CrossRef]

57. Stoltze, F.M.; Busey, E.; Taillie, L.S.; Carpentier, F.R.D. Impact of warning labels on reducing health halo effects of nutrient content claims on breakfast cereal packages: A mixed-measures experiment. Appetite 2021, 163, 105229. [CrossRef] 